\title{
Interaction Between Dislocations and Graphite Nanometric Particles in Al-Based Composites Prepared by a Solid State Route
}

\author{
I. Estrada-Guel, R. Pérez-Bustamante, C. Carreño-Gallardo, J. M. Herrera-Ramírez, R. Martínez- \\ Sánchez.
}

Centro de Investigación en Materiales Avanzados (CIMAV). Laboratorio Nacional de Nanotecnología. Miguel de Cervantes No. 120, 31109, Chihuahua, Chih., México.

Aluminium is the most widely used non-ferrous material; its use surpasses that of any other metal except iron. Reasonably pure Al is employed only when corrosion resistance and/or workability is more important than strength or hardness. When $\mathrm{Al}$ is combined with other elements to form alloys, a marked improvement on its mechanical properties is reached, but other important properties are dramatically reduced. A possible solution to this dilemma is the use of Al-based composites (AlBCs) reinforced with ceramic particles, those materials offer increased physical properties and several advantages $[1,2]$ over conventional alloys. Their properties are controlled to a large extent by the concentration, structure and characteristics of the reinforcement metal interfaces [3]. AlBCs are often prepared by powder metallurgy route [4] where a homogeneous distribution of the reinforcement particles [5] and matrix grain refining by severe plastic deformation [6] are achieved.

In this work, some AlBCs were synthesized and an evaluation of the effect of milling processing over the mechanical response of samples was carried out. Raw materials were: pure Al powder and previously metallized-graphite (MG). It was produced from graphite and copper powders milled in a high-energy Spex mill during 4h. Some Al and MG mixtures with 0, 0.5 and 1.0 (wt. \% MG) were processed in a Simoloyer mill at different time intensities. Milled samples were pressed under a uniaxial load of $950 \mathrm{MPa}$, sintered $(823 \mathrm{~K} / 3 \mathrm{~h})$ in vacuum and hot extruded in order to obtain samples for the mechanical testing. Mechanical characterization was done using an Instron universal machine and microstructural studies in a SEM JEOL model JEM-9320FIB.

Fig. 1 shows strain-stress curves of prepared AlBCs compared with pure Al, the effect of composite addition and milling intensities on mechanical response of samples is evident, but the strength enhance is associated with a marked decrease in ductility. Different strengthening mechanisms in a metallic matrix by particles can be listed: a) Dislocation lines are forced, by the microstructural constraint, to bow out or pile up, and their movement requires an extra external stress [7], b) Direct load transfer to the reinforcement, constrained plastic flow in the matrix, c) Alteration of texture and reduction of grain size caused by the dispersed particles [8]. All mechanisms produce a substantial reduction of matrix ductility. On the other hand, a smaller effect is observed in the Pure Al_2h sample as a result of particle hardening produced by cold working induced by the milling process.

Fig. 2 presents two micrographs of the Al-MG-1.0\%_2h composite after the mechanical test with a strain of $17 \%$. The observed contrast in Fig. 2A corresponds to bend contours, grain boundaries, dislocations lines and a continuous distribution of dark spots of particles below $50 \mathrm{~nm}$. These were identified, using an EDS (Fig. 2B) as carbon and copper particles which correspond to the main MG components. The presence of these nanoparticles (white arrows) causes an arrest of the dislocation lines. So, the evidence confirms the effect of $\mathrm{MG}$ addition on the mechanical properties of prepared AlBCs at macroscopic (as mechanical results show) and microscopic (STEM evidence) scales. 


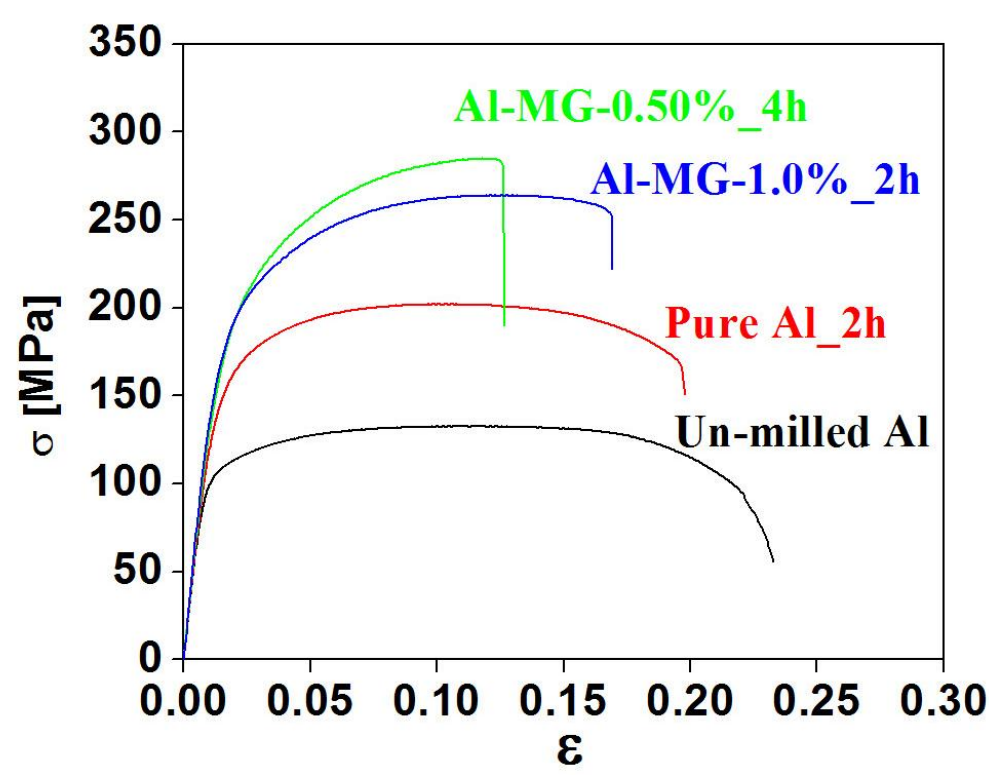

FIG. 1. Strain-stress curves of AlBCs and pure Al (milled and un-milled) used as reference. [4h corresponds to four hours of milling while $2 \mathrm{~h}$ is two hours of processing].
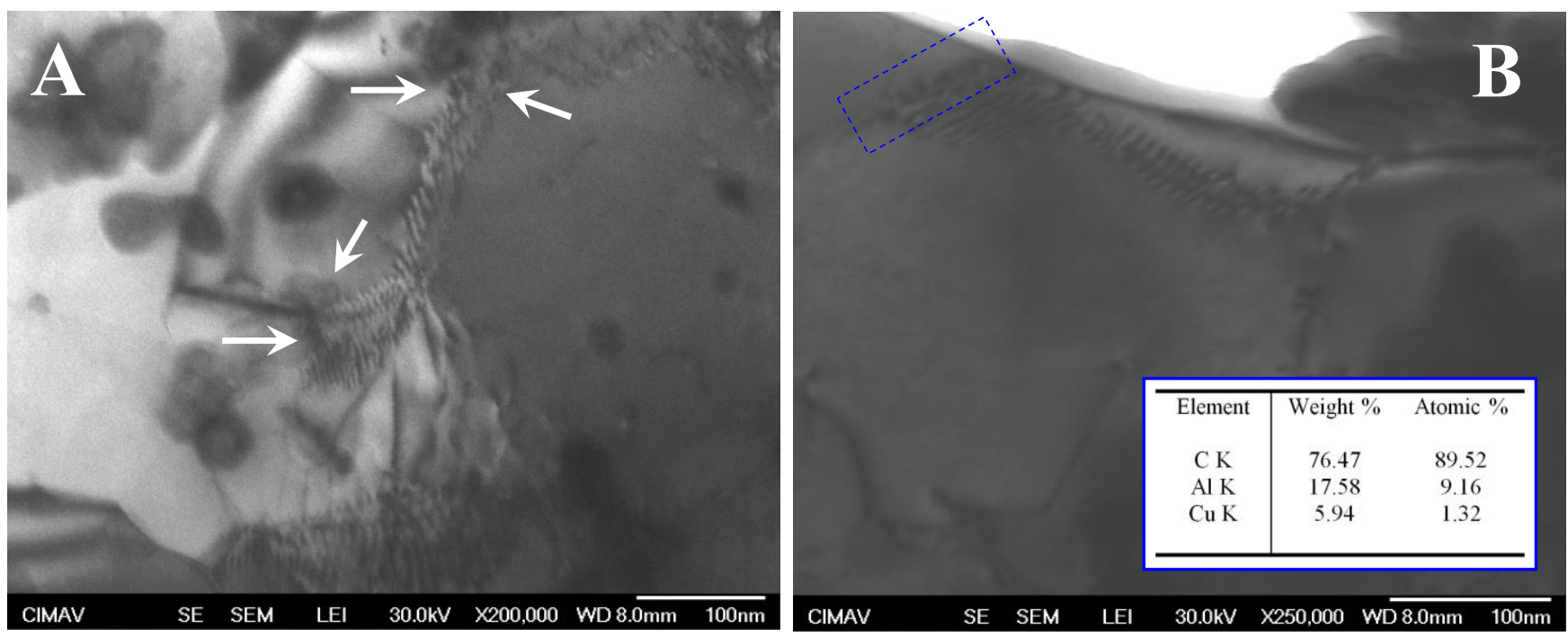

FIG. 2. STEM micrographs of an AlBC with high MG concentration after the mechanical test. A) White arrows indicate the presence of rounded MG nanoparticles and their interaction with dislocation lines. B) Dotted rectangle shows the area where the elemental microanalysis was carried out.

\section{References}

[1] Y. Zhang, N. Ma, H. Wang, Y. Le, X. Li, Mat. Design 28 (2007) 628-632.

[2] H. Wang, G. Li, Y. Zhao, G. Chen, Mat. Sci. Eng. A 527 (2010) 2881-85.

[3] A. Kostka, J. Lelatko, M. Gigla, H. Morawiec, A. Janas, Mat. Chem. Phys. 81 (2003) 323-325.

[4] A.K. Deb, P. Chatterjee, S.P. Sen Gupta. A. Mater. 52 (2004) 2755-2764.

[5] J.B. Fogagnolo, F. Velasco, M.H. Robert, J.M. Torralba. Mat. Sci. Eng. A 342 (2003) 131-143.

[6] S.C. Baik, Y. Estrin, H.S. Kim, R.J. Hellmig. Mat. Sci. Eng. A351 (2003) 86-97.

[7] M. Kouzeli, A. Mortensen, A. Mater. 50 (2002) 39-51.

[8] T.A. Khraishi, L. Yan, Y.L. Shen, Inter. J. Plast. 20 (2004) 1039-1057.

[9] This research was supported by CONACYT (106658, CHIH-2010-C01-148134) and the Redes Temáticas de Nanociencias y Nanotecnología. 